\title{
The metabolic disorders associated with chronic consumption of soft and energy drinks in rats*
}

\author{
Heba M. Eltahir ${ }^{\natural}$, Ghadi Alamri², Asmaa Alamri², Asmaa Aloufi², Maiiada Nazmy³, Saleh Ba- \\ hashwan', Hossein M. Elbadawy ${ }^{4}$, Yaser M. Alahmadi ${ }^{5}$ and Mekky M. Abouzied ${ }^{1,3}$ \\ 'Department of Pharmacology and Toxicology (subdivision of Biochemistry), College of Pharmacy, Taibah University, Medina, Kingdom of Saudi \\ Arabia; ${ }^{2}$ College of Pharmacy, Taibah University, Medina, Kingdom of Saudi Arabia; ${ }^{3}$ Department of Biochemistry, Faculty of Pharmacy, Minia \\ University, Minia, Egypt; ${ }^{4}$ Department of Pharmacology and Toxicology, College of Pharmacy, Taibah University, Medina, Kingdom of Saudi \\ Arabia; ${ }^{5}$ Departments of Clinical and Hospital Pharmacy, College of Pharmacy, Taibah University, Medina, Kingdom of Saudi Arabia
}

Background: Energy Drinks (EDs) and Soft Drinks (SDs) are widely consumed among adolescents and young adults. These drinks contain variable amounts of caffeine which is a central nervous system stimulator; in addition to sugar, taurine, vitamins and herbal extracts. Several adverse effects have been reported for the excessive consumption of caffeine and sugar. Aim: This work aimed at providing a comparison between the effect of chronic consumption of both drinks on metabolism biochemically as well as at the histopathological level. Methods: Adult albino rats were randomly divided into three groups and treated for 4 weeks. Animals received water (control, group 1), $12.5 \mathrm{ml} / \mathrm{kg} /$ day of either Pepsi (SD, group 2) or Power Horse (ED, group 3). All animals had free access to water and standard animal chow. Results: ED and SD groups showed a significant weight gain compared to control. ED animals showed a significant increase in serum urea, hyperlipidemia and hyperglycemia in comparison to control and SD groups. Serum uric acid significantly increased in ED and SD groups. ED group showed congestion and inflammation in their renal tissues in addition to splenomegaly and increased phagocyte infiltration. Conclusion: The high caffeinesugar content in ED exerts a more significant influence on the metabolic pathways than SDs. Both increase the incidence of cardiovascular diseases and tissue inflammation due to their effect on lipid profile and blood glucose. The other ingredients in EDs may play a role in the observed metabolic disturbances. Chronic use of EDs should be especially discouraged to avoid these negative effects.

Key words: energy drinks; soft drinks; hyperglycemia; splenomegaly

Received: 20 November, 2019; revised: 11 February, 2020; accepted: 27 February, 2020; available on-line: 19 March, 2020

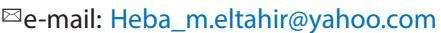

*A partial and preliminary version of the data presented in this work was presented at a student research meeting in January 2019 Abbreviations: ED, energy drink; SD, soft drink; UA, uric acid

\section{INTRODUCTION}

The consumption of caffeinated Energy Drinks (EDs) is rapidly growing and widely spreading. In response to consumer needs, many energy drinks companies appeared first in both Europe and Asia in 1960 (Reissig et al., 2009). Several surveys were conducted to measure the consumption of energy drinks in Saudi Arabia. About $33.4 \%$ of students at Taibah University declared regular consumption of energy drinks in 2018, whereas $52.2 \%$ of the students in a female secondary school had consumed EDs in 2011 (Katib et al., 2018; Aluqmany et al., 2013). An additional study in three universities in Saudi Arabia showed that about $70 \%$ of students regularly consumed EDs (Aljaloud, 2016). As for the ingredients, it must be mentioned that the main components of EDs are caffeine and carbohydrates; the content of caffeine is high and varies among the products of the different companies. They also contain other ingredients such as guarana, taurine, and B vitamins.

The advertisement of EDs claims that drinking an ED can provide energy for the body and the mind as well. Consumers use energy drinks for several reasons like enjoying with friends or improving their activity such as in studying, staying awake for a longer time, driving or for athletic performance (Ibrahim et al., 2014). Despite the wide spread of EDs consumption among students for the previously mentioned reasons, a study found that there is a negative correlation between increased consumption of EDs and the grade point average (GPA) (Champlin et al., 2016). In addition, the prolonged and chronic consumption of these drinks was recently linked to variable health concerns.

It was found that EDs induce several adverse effects but the most common is cardiovascular, neurological, and liver impairment, with no positive effect on the memory process (Ali et al., 2015; Nieradko-Iwanicka \& Pośnik, 2016). Theses side effects were mainly related to the high content of caffeine in addition to the effect of the other ingredients included in these drinks (Gheith, 2017).

Regarding soft drinks (SDs), their primary component is the monosaccharide fructose. There are many reports emphasizing that consumption of high-sugar beverages increases the risk of type-two diabetes (Imamura et al., 2015). It was reported that fructose consumption increases hepatic lipogenesis and induces ATP depletion, and thereby increases hepatic uric acid (UA) production. Altered lipid metabolism and diabetes are both known risk factors for the development and progression of non-alcoholic fatty liver disease. Some studies showed a $20 \%$ relative increase in UA in subjects receiving sugarsweetened soft drinks compared to semi-skimmed milk or water (Imamura et al., 2015).

In this study, we aimed at evaluating and comparing the metabolic disorders induced by consumption of soft and energy drinks in rats. 


\section{MATERIALS AND METHODS}

Animals and experiment design. Twenty-four adult male albino rats of $200 \pm 30 \mathrm{~g}$ average body weight were utilized to study the effect of soft and energy drinks on the metabolic parameters. Rats were housed in standard laboratory conditions $\left(23-25^{\circ} \mathrm{C}, 50-55 \%\right.$ humidity, $12 / 12 \mathrm{~h}$ light/dark cycle) and were randomized into three groups, eight animals each.

Group I: control group animals received standard chow and water ad libitum.

Group II: soft drink group received orally $12.5 \mathrm{ml} \mathrm{SD}$ $\left(\mathrm{Pepsi}^{\circledR}\right) / \mathrm{kg} /$ day along with free access to standard chow and water.

Group III: energy drinks group received orally $12.5 \mathrm{ml} \mathrm{ED}$ (Power Horse $\left.{ }^{\circledR}\right) / \mathrm{kg} /$ day along with free access to standard chow and water.

All animals were housed in plastic cages at controlled temperature, relative humidity and air flow conditions with fixed 12 hours light-dark cycles. Animals were handled according to the national laws on the care and use of laboratory animals and the Guide for the Care and Use of Laboratory Animals (1996, published by National Academy Press, 2101 Constitution Ave. NW, Washington, DC 20055, USA) and the protocol was approved by the institutional review board.

The ingredients of both ED and SD are listed in Table 1. Rats were weighed on Mondays on a weekly basis for the whole period of the experiment (4 weeks).

Tail-flick test. Animals from the different groups were restrained and their tails were exposed to an IRheat source that was restricted to the middle part of the tail using $\mathrm{Ugo}^{\circledR}$ basile thermal stimulation unit $\left(\mathrm{Ugo}^{\circledR}\right.$ basile SRL, Gemonio, Italy) according to the manufacturer's instructions. The device records the latency time before the animal's sense of pain causes it to moves its tail away from the IR source.

Blood and tissue samples collection. By the end of the fourth week, the experiment was brought to an end by sacrificing animals after an overnight fasting period (water was provided ad libitum). Blood samples were collected by cardiac puncture and allowed to clot before separating serum at $3000 \mathrm{rpm}$ for 25 minutes at $4^{\circ} \mathrm{C}$ and collected serum samples were stored at $-70^{\circ} \mathrm{C}$ till use.

Tissue samples (kidney, liver, spleen, and heart) were collected, briefly rinsed in normal saline and weighed before being fixed in 4\% paraformaldehyde solution for histological examination.
Biochemical analysis. For biochemical analysis blood glucose, UA, triglycerides, urea, creatinine and cholesterol were estimated using commercially available kits according to manufacturers' instructions.

Histopathology. Tissues to be histologically investigated were dehydrated in a series of increasing alcohol concentrations then cleared in xylene before embedding in paraffin. Sections of $5 \mu \mathrm{m}$ thickness were cut from the corresponding tissue blocks, deparaffinized, hydrated and cleared to be stained with hematoxylin/eosin for histopathological investigation.

\section{RESULTS}

\section{Weight change and relative organ weight}

A normal diet with water along with the administration of the different drinks resulted in an increase in animals' weight over the period of the experiment in SD and ED groups.

The percentage of weight gain was higher in the ED group $(36 \%)$ when compared to control and SD groups as presented in Table 2. Weight increase was calculated by subtracting the initial weight from the final weight and dividing the difference by the initial weight and multiplying the result by 100 .

Regarding the isolated organs a change in the relative weight of some organs was observed among the three test groups. As shown in Table 3 no significant difference was observed in kidney as well as heart weight by the end of the experiment between the three groups. Interestingly, a significant increase in spleen relative weight was observed in ED as well as SD group animals after 4 weeks. This represented an increase in spleen weight by almost $46 \%$ and $42 \%$ over the healthy control weight in ED and SD group respectively. In addition, a significant reduction in liver weight was also observed in SD animals (by about 26\%). The relative weight of the organs was obtained by dividing the wet weight of the organ by the total weight of the animal directly before the sacrifice. Values are presented as mean relative weight, $n=8$, $* p<0.01$ compared to the control.

\section{Effect of the different drinks on pain threshold}

The pain threshold of the animals from the different groups was tested by exposing them to a painful

Table 1. Nutritional information for the used energy drink and soft drink

\begin{tabular}{|c|c|c|}
\hline Nutritional information per $100 \mathrm{ml}$ & ED (Power horse ${ }^{\circ}$ ) & SD (Pepsi $\left.{ }^{\circ}\right)$ \\
\hline Energy (Kcal) & $45 \mathrm{kcal}$ & $42 \mathrm{kcal}$ \\
\hline Fat $(g)$ & 0 & 0 \\
\hline Carbohydrates (g) & 10.7 & 11 \\
\hline Saturated fat (g) & 0 & 0 \\
\hline Fiber $(g)$ & 0 & 0 \\
\hline Protein (g) & 0 & 0 \\
\hline Caffeine (mg) & 32 & 10 \\
\hline Taurine $(g)$ & 0.4 & 0 \\
\hline Riboflavin & $0.06 \mathrm{~g}$ & 0 \\
\hline Niacin & $8.00 \mathrm{mg}$ & 0 \\
\hline Vitamin B6 & $2.00 \mathrm{mg}$ & 0 \\
\hline Pantothenic acid & $2.00 \mathrm{mg}$ & 0 \\
\hline
\end{tabular}


Table 2. Effect of the different treatments on live body weight

\begin{tabular}{llllll}
\hline & Initial weight & Week 2 & Weight increase in \% & Week 4 & Weight increase in \% \\
\hline Control & $214 \mathrm{~g} \pm 4.3$ & $234 \mathrm{~g} \pm 7.4$ & 9.3 & $255.3 \mathrm{~g} \pm 10.5$ & 19.2 \\
\hline SD & $204 \mathrm{~g} \pm 8.5$ & $251.8 \mathrm{~g} \pm 7.1$ & 23.4 & $260.4 \mathrm{~g} \pm 6.3$ & 27.6 \\
\hline ED & $194.8 \mathrm{~g} \pm 8.4$ & $228.3 \mathrm{~g} \pm 9.5$ & 17.2 & $265.6 \mathrm{~g} \pm 4.7$ & 36.3 \\
\hline
\end{tabular}

Values are presented as mean \pm S.E.M., $n=8$.

Table 3. Relative average organ weight obtained from the different groups

\begin{tabular}{llll}
\hline & Ctrl & SD & ED \\
\hline Heart & $0.0034 \pm 2.2 \times 10^{-4}$ & $0.0038 \pm 3.2 \times 10^{-4}$ & $0.0035 \pm 2.4 \times 10^{-4}$ \\
\hdashline Liver & $0.0335 \pm 7 \times 10^{-4}$ & $0.0284^{*} \pm 15 \times 10^{-4}$ & $0.0324 \pm 2 \times 10^{-4}$ \\
\hline Kidney & $0.0032 \pm 36 \times 10^{-5}$ & $0.0033 \pm 28 \times 10^{-5}$ & $0.0035 \pm 25 \times 10^{-5}$ \\
\hdashline Spleen & $0.0024 \pm 25 \times 10^{-5}$ & $0.0034^{*} \pm 27 \times 10^{-5}$ & $0.0035^{*} \pm 23 \times 10^{-5}$ \\
\hline
\end{tabular}

Values are presented as mean \pm S.D., $n=8 .{ }^{*} p<0.05$

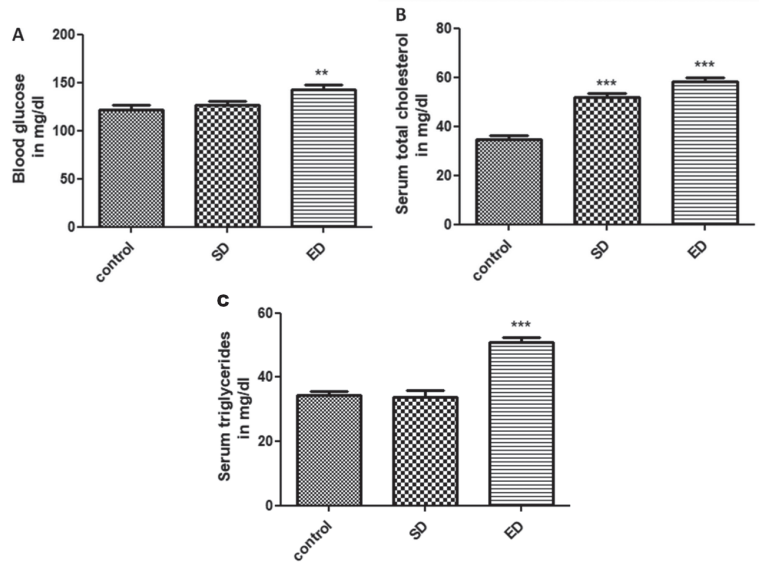

Figure 1. Effect of the different treatments on pain threshold of the animals.

Values are presented as mean \pm S.E.M., $\mathrm{n}=8$. ${ }^{* * *} p<0.001$, compared to control.

IR stimulus using tail-flick latency device. Interestingly, animals treated with ED and SD showed a very statistically significant increase in pain tolerance compared to controls $(p<0.005$ and $p<0.01$, respectively) observed as an increase in the time elapsed before the animal moved its tail away from the heat source (Fig. 1). Although the use of ED induced a stronger pain tolerance effect compared to SD, the difference between both groups was statistically non-significant $(p>0.02)$.

\section{Effect of the different treatments on fasting blood glucose and serum lipid profile}

Fasting blood glucose was another parameter that was assessed at the end of the experiment. A significant in-

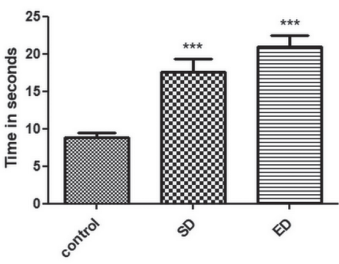

Figure 2. Effect of the different treatments on fasting blood glucose and serum lipid profile.

Values are presented as mean \pm S.E.M., $\mathrm{n}=8$ per group.

crease in fasting blood glucose was detectable in the ED group after 4 weeks of continuous administration when compared to the control group. Interestingly, animals treated with SD for the same period of time showed fasting blood glucose values that were comparable to healthy controls ( $p>0.06$; Fig. 2A).

Serum triglycerides and serum total cholesterol showed a highly significant increase in ED group after 4 weeks when compared to healthy control and SD group animals $(p<0.005$; Figs $2 \mathrm{~B}$ and $2 \mathrm{C})$. However, SD animals showed a significant increase in their serum cholesterol $(p<0.005)$ but no significant change in their serum triglycerides levels compared to healthy control animals (Figs 2B and 2C).

\section{Effect of the different drinks on serum urea, creatinine and uric acid levels}

Assessment of serum levels of urea and uric acid revealed a significant increase in the ED group in samples collected at the end of the experiment. On the other hand, a significant increase in serum uric acid was observed only in SD-treated animals but no significant changes in serum urea levels could be detected in this test group when compared to healthy control (Figs 3A and $3 \mathrm{~B})$. A non-significant increase in serum creatinine was observed in the ED group as well as in the SD group when compared to the control group (Fig. 3C).

\section{Histopathological investigation}

Examination of H\&E-stained sections from the spleen of the different groups revealed pathological changes in ED and SD group, in the form of congested and dilated lymphatic sinuses and increased phagocyte counts (Fig. 4A, B and C, Table 4). Whereas the architecture of spleen and the splenic capsule were preserved in all

Table 4. Histopathological evaluation of the splenic tissue in the different groups

\begin{tabular}{lllll}
\hline Group & Architecture & Splenic capsule & Lymphoid follicles & Red pulp \\
\hline Control & Preserved & Normal & $\begin{array}{l}\text { Slightly expanded follicles } \\
\text { Reactive pale germinal centers }\end{array}$ & $\begin{array}{l}\text { Normal lymphatic sinuses } \\
\text { Few phagocytic cells }\end{array}$ \\
\hdashline SD & Preserved & Normal & $\begin{array}{l}\text { Slightly expanded follicles } \\
\text { Reactive pale germinal centers }\end{array}$ & $\begin{array}{l}\text { Dilated lymphatic sinuses } \\
\text { Mildly increased number of phagocytic } \\
\text { cells }\end{array}$ \\
\hdashline ED & Preserved & Normal & $\begin{array}{l}\text { Nodular appearance } \\
\text { Significantly expanded follicles } \\
\text { Reactive pale germinal centers }\end{array}$ & $\begin{array}{l}\text { Dilated lymphatic sinuses } \\
\text { Increased number of phagocytic cells }\end{array}$ \\
\hline
\end{tabular}




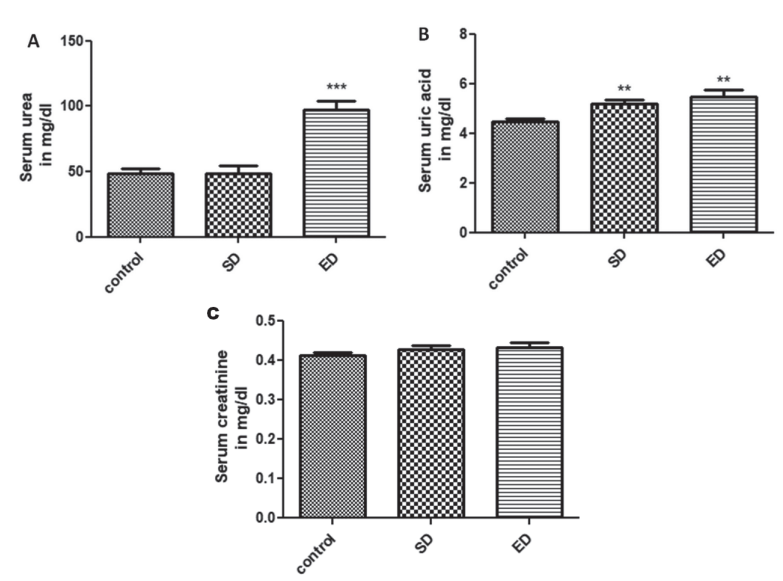

Figure 3. Effect of the different treatments on serum urea, uric acid and creatinine. Values are presented as mean \pm S.E.M., $n=8$.

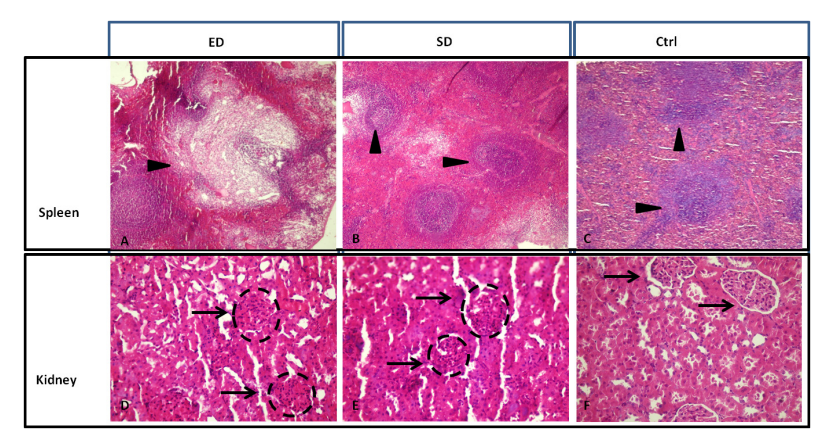

Figure 4. Histopathological examination of the spleen $(\mathbf{A}-\mathbf{C})$ and kidney (D-F) sections from the different groups stained with $\mathrm{H} \& \mathrm{E}$.

Black arrowheads point at lymphatic sinuses in spleen sections ( $A$, $B$ and $C$ ), and arrows point at glomeruli (enclosed by dotted circles) in kidney tissue sections (D, E and F).

ED SD

Ctrl

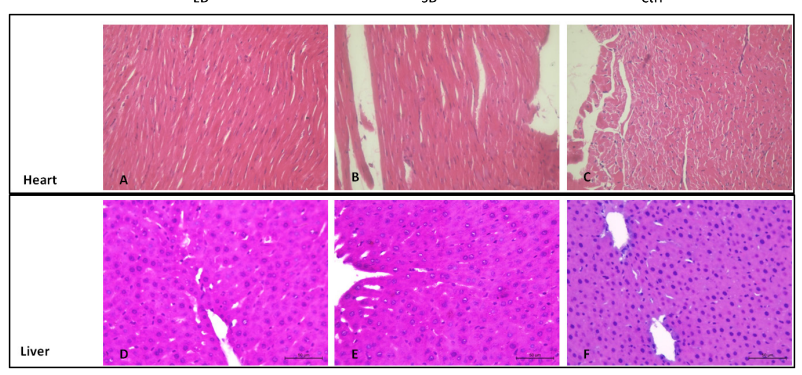

Figure 5. Histopathological examination of the heart $(A-C)$ and liver (D-F) sections from the different groups stained with $H \& E$. No pathological changes can be observed in both tissues in the different test groups.

groups, lymphoid follicles and red pulp showed pathological differences as shown in Table 4.

Upon investigating kidney tissue samples from the different groups, no signs of necrosis or hemorrhage were observed in the different groups. Also, inflammation was not detectable in neither control nor SD animals, whereas ED animals showed a mild inflammatory response. Animals receiving $\mathrm{ED}$ or $\mathrm{SD}$ showed various degrees of hypercellular glomeruli (arrows, Figs 4D and E), which were not detected in control animals (Fig. 4F). Interestingly, only
ED-treated animals showed signs of congestion within the capillary tufts. All groups showed normal tubule structure and differentiated cortex and medulla (Figs 4D-4F).

No pathological manifestations were observed in the heart (Figs 5A-5C) or liver sections (Figs 5D-5F) obtained from the different groups.

\section{DISCUSSION}

The energy as well as carbonated soft drinks have become a part of the youth culture and have been increasingly consumed among adults and young adults on different occasions all over the world (Malinauskas et al., 2007; Dwaidy et al., 2018). However, several research articles showed multiple negative effects of the consumption of energy and soft drinks. The consumers claim that these drinks, especially energy drinks, provide them with the energy required for stressful situations, or for staying awake for a longer time (Nowak \& Jasionowski, 2015).

The stimulative effect of these drinks is attributed to their content of vitamins, taurine, guarana and other ingredients, but first comes their high content of caffeine, the most widely consumed CNS stimulant in the world. Caffeine is an adenosine antagonist inducing neurotransmitter release, and phosphodiesterase inhibitor, modifying intracellular cAMP levels and stimulating glucose metabolism and lipolysis (Harpaz et al., 2017; Horrigan et al., 2004).

Moreover, each can of such sugar-sweetened drink provides about 30 grams of sugar; an amount that by far exceeds the recent recommendations of the WHO. This high sugar content elicits a deleterious effect on various metabolic processes related to glucose, lipids, ketone bodies and proteins (Boulton et al., 2016). The consumption of drinks containing both sugar and caffeine was strongly linked to a higher incidence of several disorders related to glucose metabolism such as obesity, type-2 diabetes and cardiovascular diseases (Narain et al., 2016; Greenwood et al., 2014).

The epidemic of energy drinks consumption is also widely spread in the Saudi community, as Saudi Arabia is classified among the top ten countries when it comes to energy drinks consumption (Rahamathulla, 2017). In this study, we aimed at investigating and comparing the hazardous effects of chronic consumption of energy and soft drinks on the biochemical and histological level in rat animal model.

In our study, a significant increase was observed in fasting blood glucose in ED-treated rats compared to the control or SD group. These findings are in agreement with previously reported results that revealed a significant alteration in blood glucose after ED administration (Nowak et al., 2018). Interestingly, SD administration did not result in a significant increase in fasting blood glucose compared to the controls.

In fact, the high carbohydrate content in the tested drinks caused an increase in blood glucose, which consequently elicits a condition of hyperinsulinemia, which negatively affects the whole metabolic process (Macdonald, 2016). Although both tested drinks have nearly the same carbohydrate content, the hyperglycemia was observed only in ED animals. This can be explained by the caffeine content, which was reported to augment hyperinsulinemia via multiple mechanisms that include increasing the circulating epinephrine and cortisol levels, decreasing tissue sensitivity and inhibiting glucose utilization, and consequently maintaining high levels of blood glucose (Keijzers et al., 2002). The high caffeine content in ED in addition to its carbohydrate content represents a glucose-caffeine combination that effectively modifies the metabolic re- 
sponse towards the increase in circulating glucose, and explains the intense hyperglycemic effect that was detected in ED animals but not in SD animals. It is also possible that the niacin present in the EDs augments their hyperglycemic effect compared to the niacin-free SD as reported by some studies that connected niacin in the diet to hyperglycemic outbreaks (Zhou et al., 2010).

This persistent hyperglycemia is thought to provoke a condition of oxidative stress that results from the production of glycation end products and denaturation of various macromolecules resulting in cellular damage in various organs (Nagai et al., 2014).

In addition to its effect on blood glucose, ED administration caused animals to show a significant increase in their serum triglyceride and cholesterol levels compared to control animals. This agrees with the findings of other groups that reported alteration in lipid profile of such animals (Sadowska, 2012). The augmented hyperglycemic and, consequently, the hyperinsulinemic state that results from sugar-caffeine combination modulates lipid metabolism upon consumption of $\mathrm{ED}$, favoring the glycolytic pathways and blocking lipolysis via the inhibitory effect of insulin on hormone-sensitive lipase (Schaefer et al., 2009).

It is worth to note that SD animals did not show a significant change in their serum triglycerides when compared to control animals, which coincides with their blood glucose levels that were also non-significantly different from controls. This finding introduces an additional proof for the role played by caffeine in augmenting glucose effect on the metabolism, as an ED contains at least three times more caffeine as a regular caffeinated SD (Ugwuja, 2014; Gonzalez-Dominguez et al., 2017).

Chronic consumption of ED or SD along with the regular diet caused the animals to experience a significant weight gain when compared to the control animals. In this aspect, a strong association was established between the consumption of sugar-sweetened beverages (SSBs) and the incidence of obesity and obesity-related disorders such as type- 2 diabetes and cardiovascular diseases as reported earlier (Mattioli et al., 2018; Hu, 2013). Interestingly, weight gain had a similar tendency to that observed in fasting blood glucose, as ED animals gained the most weight and control animals gained the least weight by the end of the experiment.

The significant improvement in the pain threshold is one positive effect that was observed in animals consuming either SD or ED compared to the control ones, which can be ascribed to their caffeine content. However, the other observed effects including hyperglycemia, hyperlipidemia and obesity, in addition to the previously reported effects of these drinks on blood pressure and heart rate, excitation and palpitation suggest the regular consumption of ED, especially over a long period of time, as a possible risk factor for CVS (Ugwuja, 2014; Nowak et al., 2018).

Both serum urea and uric acid were also significantly elevated in animals consuming ED. Urea, creatinine and uric acid are byproducts of protein and amino acid catabolism that are normally excreted via the kidney filtration, however, renal damage can affect their excretion resulting in their increased level in the circulation (Ebuehi et al., 2011).

The increase in urea and uric acid level here can be attributed to caffeine via its inhibitory effect on A2A adenosine receptors (Tofovic et al., 2007). Another possible explanation for the alteration in these parameters is the ureainduced activation of xanthine oxidase, which accelerates the rate of uric acid biosynthesis from xanthine (Obochi et al., 2010). In contrast to previous studies that reported a significant increase in serum creatinine levels, no significant changes were detected in the current study which can be explained by the shorter experimentation period in this study compared to the previous reports (Mansy et al., 2017). Peroxide free radicals are excessively produced as a result of the oxidative stress induced by the persistent hyperglycemia, eliciting renal oxidative damage in the form of interstitial inflammation, increased proteinuria and histopathological changes of the renal tissue (Gheith, 2017). Despite the absence of significant differences in the relative kidney weight among the different groups, these pathological changes were histologically detectable in kidney tissues derived from the ED-group which showed various signs of congestion and inflammation when compared to SD or control animals. Congestion in this context can be explained by the vasodilator effects of caffeine that can induce changes in the microcirculation and hence congestion (Khayyat, 2014).

Several research groups had reported various histopathological changes in different organs upon ED administration including liver, stomach, pancreas and submandibular glands but not the spleen (Khayyat et al., 2012.; Ayuob \& ElBeshbeishy, 2016; Kassab \& Tawfik, 2018).

In the current study, careful examination of the splenic tissue revealed cytological changes in response to caffeinated ED, where dilated lymphatic sinuses and increased number of phagocytes along with prominently expanded follicles were observed. Similar but less distinct changes were observed in SD animals. Follicular hyperplasia in these animals could be explained by B-cells proliferation that takes place in response to various factors. As mentioned previously, prolonged hyperglycemia causes oxidative stress that consequently induces a condition of chronic inflammation, and hence, modulates splenic function and structure. Splenomegaly, altered spleen morphology and upregulation of inflammatory cytokines were reported in animals fed a high-fat/high-sugar diet which also induced prolonged hyperglycemia in the tested animals (Altunkaynak et al., 2007). Another research group investigated the effect of ED administration for 4 weeks on the blood cell count and detected a reduction in erythrocyte counts in these animals (Khayyat et al., 2014). The splenomegaly observed in our study can be ascribed to the increase in the content of phagocytic cells, which are responsible for the phagocytosis of erythrocytes (Unruh et al., 2015). Connecting these findings together, one can assume that the low erythrocytes counts upon ED consumption may result from the shortening of their lifespan. This, in turn, introduces an excessive load on the spleen to remove these erythrocytes and induces the increase in the number of phagocytes within the spleen and consequently splenomegaly. It is to be noted that both heart and liver tissues did not show pathological changes despite the biochemical changes observed in the animals' lipid profile. This can possibly be assigned to the relatively short duration of the current experiment in comparison to the other studies that showed changes in the liver tissue after 12 weeks of ED administration (Mansy et al., 2017).

In conclusion, EDs and SDs are both hazardous and represent risk factors for cardiovascular disorders as well as kidneys and spleen diseases. Their effects are mainly mediated by their hyperglycemic effect which induces oxidative stress and hence tissue and organ damage.

\section{Conflict of interest}

The authors do not have a conflict to declare

\section{Author contribution}

Heba M. Eltahir, Ghadi Almoghamsi, Asmaa Monawer, and Asmaa Alofi contributed to the conception of the idea and experimental design in addition to the analysis and interpretation of the data. Maiiada Nazmy 
took part in histochemical analysis and writing the manuscript. Hossein Elbadawy was responsible for the animal care and drinks administration, collecting data and revising the manuscript. Saleh Bahashwan contributed to manuscript preparation and the critical revision of the manuscript. Mekky M. Abouzied contributed to the interpretation of the data and the critical revision of the manuscript and the final approval of the version to be published.

All authors read and approved the final manuscript.

\section{REFERENCES}

Ali F, Rehman H, Babayan Z, Stapleton D, Joshi DD (2015) Energy drinks and their adverse health effects: A systematic review of the current evidence. Postgrad Med 127: 308-322. https://doi.org/10.108 $0 / 00325481.2015 .1001712$

Aljaloud O (2016) Use of energy drinks among College Students in Saudi Arabia. Am I Sports Sci 4: 6

Altunkaynak BZ, Ozbek E, Altunkaynak ME (2007) A stereological and histological analysis of spleen on obese female rats, fed with high fat diet. Saudi Med J 28: 353-357. PMID: 17334458

Aluqmany RMR, Saad U, Abdullah R, Ahamd A (2013) Consumption of energy drinks among female secondary school students, Almadinah Almunawwarah, Kingdom of Saudi Arabia, 2011. J Taibab Univ Med Sci 8: 6

Ayuob N, ElBeshbeishy R (2016) Impact of an energy drink on the structure of stomach and pancreas of albino rat: can omega- 3 provide a protection? PLoS One 11: e0149191. https://doi.org/10.1371/ journal.pone.0149191

Boulton J, Hashem KM, Jenner KH, Lloyd-Williams F, Bromley H, Capewell S (2016) How much sugar is hidden in drinks marketed to children? A survey of fruit juices, juice drinks and smoothies. BMJ Open 6: e010330. https://doi.org/10.1136/bmjopen-2015-010330

Champlin SE, Pasch KE, Perry CL (2016) Is the consumption of energy drinks associated with academic achievement among college students? J Prim Prev 37: 345-359. https://doi.org/10.1007/s10935016-0437-4

Dwaidy J, Dwaidy A, Hasan H, Kadry S, Balusamy B (2018) Survey of energy drink consumption and adverse health effects in Lebanon. Health Inf Sci Syst 6: 15. https://doi.org/10.1007/s13755-018-0056-y

Ebuehi OA, Ajayl OE, Onyeulor AL, et al. (2011) Effects of oral administration of energy drinks on blood chemistry, tissue histology and brain acetylcholine in rabbits. Nig Q J Hosp Med 21: 29-34. PMID: 21913538

Gheith I (2017) Clinical Pathology of caffeinated and non-caffeinated energy drinks: Review. Life Sci J 14: 16

Gonzalez-Dominguez R, Mateos RM, Lechuga-Sancho AM, GonzálezCortés JJ, Corrales-Cuevas M, Rojas-Cots JA, Segundo C, Schwarz M (2017) Synergic effects of sugar and caffeine on insulin-mediated metabolomic alterations after an acute consumption of soft drinks. Electrophoresis 38: 2313-2322. https://doi.org/10.1002/ elps.201700044

Greenwood DC, Threapleton DE, Evans CE, Cleghorn CL, Nykjaer C, Woodhead C, Burley VJ (2014) Association between sugarsweetened and artificially sweetened soft drinks and type 2 diabetes: systematic review and dose-response meta-analysis of prospective studies. $\mathrm{Br} J$ Nutr 112: 725-734. https://doi.org/10.1017/ S0007114514001329

Harpaz E, Tamir S, Weinstein A, Weinstein Y (2017) The effect of caffeine on energy balance. J Basic Clin Physiol Pharmacol 28: 1-10. https://doi.org/10.1515/jbcpp-2016-0090

Horrigan LA, Kelly JP, Connor TJ (2004) Caffeine suppresses TNFalpha production via activation of the cyclic AMP/protein kinase A pathway. Int Immunopharmacol 4: 1409-1417. https://doi. org/10.1016/j.intimp.2004.06.005

Hu FB (2013) Resolved: there is sufficient scientific evidence that decreasing sugar-sweetened beverage consumption will reduce the prevalence of obesity and obesity-related diseases. Obes Rev 14: 606619. https://doi.org/10.1111/obr.12040

Ibrahim NK IR, Murad M, Fida H, Abalkhaeil B, Al Ahmadi J (2014) Energy drinks consumption amongst medical students and interns from three colleges in Jeddah, Saudi Arabia. J Food Nut Res 2: 6

Imamura F, O'Connor L, Ye Z, Mursu J, Hayashino Y, Bhupathiraju SN, Forouhi NG (2015) Consumption of sugar sweetened beverages, artificially sweetened beverages, and fruit juice and incidence of type 2 diabetes: systematic review, meta-analysis, and estimation of population attributable fraction. BMJ 351: h3576. https://doi. org/10.1136/bmj.h3576

Kassab AA, Tawfik, SM (2018) Effect of a caffeinated energy drink and its withdrawal on the submandibular salivary gland of adult male al- bino rats: A histological and immunohistochemical study. Egyptian I Histol 41: 11-26. https://doi.org/10.21608/EJH.2018.7518

Katib AAAH, Surrati A, Zeidan ZA (2018) Energy Drink Consumption among College Students in Saudi Arabia. J Food Nut Res 6: 6. https://doi.org/10.12691/jfnr-6-8-8

Keijzers GB, De Galan BE, Tack CJ, et al. (2002) Caffeine can decrease insulin sensitivity in humans. Diabetes Care 25: 364-369

Khayyat L, Essawy A, Sorour J, Al Rawi M (2014) Impact of some energy drinks on the structure and function of the kidney in wistar albino rats. Life Sci J 11: 9.

Khayyat L, Sorour J, Al Rawi M, Essawy A (2012) Histological, ultrastructural and physiological studies on the effect of different kinds of energy drinks on the liver of swiss albino rat. J Ame Sci 8: 688-697

Khayyat LI, Essawy AE, Al Rawy MM, Sorour JM (2014) Comparative study on the effect of energy drinks on haematopoietic system in Wistar albino rats. J Environ Biol 35: 883-891. PMID: 25204063

Macdonald IA (2016) A review of recent evidence relating to sugars, insulin resistance and diabetes. Eur J Nutr 55: 17-23. https://doi. org/10.1007/s00394-016-1340-8

Malinauskas BM, Aeby VG, Overton RF, Carpenter-Aeby T, BarberHeidal K (2007) A survey of energy drink consumption patterns among college students. Nutr J 6: 35 . https://doi.org/10.1186/14752891-6-35

Mansy W, Alogaiel, D, Hanafi M, Zakaria E (2017) Effects of chronic consumption of energy drinks on liver and kidney of experimental rats. Tropical J Pharm Res 16: 2849-2856

Mattioli AV, Manenti A, Bonetti LR, Farinetti A (2018) Energy drinks and obesity: Preliminary results from a preclinical study. Anatol J Cardiol 19: 422. https://doi.org/10.14744/AnatollCardiol.2018.25826

Nagai R, Shirakawa J, Fujiwara Y, Ohno R, Moroishi N, Sakata N, Nagai M (2014) Detection of AGEs as markers for carbohydrate metabolism and protein denaturation. J Clin Biochem Nutr 55: 1-6. https://doi.org/10.3164/jcbn.13-112

Narain A, Kwok CS, Mamas MA (2016) Soft drinks and sweetened beverages and the risk of cardiovascular disease and mortality: a systematic review and meta-analysis. Int J Clin Pract 70: 791-805. https://doi.org/10.1111/ijcp.12841

Nieradko-Iwanicka B, Pośnik K (2016) Prolonged consumption of energy drinks does not affect the processes of memory, and increases the activity of transaminases, and cholesterol concentration- animal model study results. Family Med Primary Care Rev 18: 4.

Nowak D, Goslinski M, Nowatkowska K (2018) The effect of acute consumption of energy drinks on blood pressure, heart rate and blood glucose in the group of young adults. Int J Environ Res Public Health 15. https://doi.org/10.3390/ijerph15030544

Nowak D, Jasionowski A (2015) Analysis of the consumption of caffeinated energy drinks among Polish adolescents. Int $J$ Environ Res Public Health 12: 7910-7921. https://doi.org/10.3390/ijerph120707910

Obochi GO, Amali OO, Ochalefu DO (2010) Effect of melatonin and caffeine interaction on caffeine induced oxidative stress and sleep disorders. Niger J Physiol Sci 25: 17-24. PMID: 22314898

Rahamathulla MP (2017) Prevalence, side effects and awareness about energy drinks among the female university students in Saudi Arabia. Pak J Med Sci 33: 6. https://doi.org/10.12669/pjms.332.12084

Reissig CJ, Strain EC, Griffiths RR (2009) Caffeinated energy drinks - a growing problem. Drug Alcobol Depend 99: 1-10. https://doi. org/10.1016/j.drugalcdep.2008.08.001

Sadowska J (2012) Evaluation of the effect of consuming an energy drink on the concentration of glucose and triacylglycerols and on fatty tissue deposition. A model study. Acta Sci Pol Technol Aliment 11: 311-318. PMID: 22744952

Schaefer EJ, Gleason JA, Dansinger ML (2009) Dietary fructose and glucose differentially affect lipid and glucose homeostasis. J Nutr 139: 1257S-1262S. https://doi.org/10.3945/jn.108.098186

Tofovic SP, Salah EM, Jackson EK, Melhem M (2007) Early renal injury induced by caffeine consumption in obese, diabetic ZSF1 rats. Ren Fail 29: 891-902. https://doi.org/10.1080/08860220701569846

Ugwuja E (2014) Biochemical effects of energy drinks alone or in combination with alcohol in normal albino rats. Adv Pharm Bull 4: 69-74. https://doi.org/10.5681/apb.2014.011

Unruh D, Srinivasan R, Benson T, Haigh S, Coyle D, Batra N, Keil R, Sturm R, Blanco V, Palascak M, Franco RS, Tong W, Chatterjee T, Hui DY, Davidson WS, Aronow BJ, Kalfa T, Manka D, Peairs A, Blomkalns A, Fulton DJ, Brittain JE, Weintraub NL, Bogdanov VY (2015) Red blood cell dysfunction induced by high-fat diet: potential implications for obesity-related atherosclerosis. Circulation 132: 18981908. https://doi.org/10.1161/CIRCULATIONAHA.115.017313

Zhou SS, Li D, Zhou YM, Sun WP, Liu QG(2010) B-vitamin consumption and the prevalence of diabetes and obesity among the US adults: population based ecological study. BMC Public Health 10: 746. https://doi.org/10.1186/1471-2458-10-746 